\title{
Effects of Bacillus subtilis on growth performance, serum parameters, digestive enzyme, intestinal morphology, and colonic microbiota in piglets
}

\author{
Bo Deng ${ }^{1}$, Jie Wu ${ }^{1}$, Xiaohui $\mathrm{Li}^{2}$, Cheng Zhang ${ }^{3}$, Xiaoming Men ${ }^{1}$ and Ziwei $\mathrm{Xu}^{1 *}$ (i)
}

\begin{abstract}
The present study was conducted to investigate effects of Bacillus subtilis on growth performance, serum parameters, digestive enzymes, intestinal morphology, and colonic microbiota in piglets. A total of 72 piglets were weighed and randomly allotted into three treatments (four replication pens per treatment with six piglets/pen) for a 28-day experiment. The dietary treatments were as follows: basal diet (control group, CTR), basal diet supplementation with antibiotic (antibiotic group, ABT), and basal diet supplementation with $0.1 \%$ Bacillus subtilis (probiotic group, PBT). The average daily gain of body weight increased in both the ABT and PBT groups, and dietary antibiotics decreased the feed:gain ratio (F:G), as compared to the CTR group $(P<0.05)$. Both ABT and PBT piglets had increased serum triglycerides and lipase, amylase, maltase activities and villus height:crypt depth ratio $(V / C)$ in ileum $(P<0.05)$. The PBT group also showed an increase in serum glucose and villus height in the ileum $(P<0.05)$. Dietary antibiotics increased Lactobacillus johnsonii, as compared to the CTR group, but decreased bacterial diversity and increased Escherichia coli, as compared to the PBT group $(P<0.05)$. Piglets dietary with $B$. subtilis modulated the microbiota by increasing the abundance of Firmicutes (L. johnsonii, L. reuteri) and decreasing the abundance of E. coli, as compared to the control group $(P<0.05)$. These results indicate that dietary of $B$. subtilis improves growth performance and intestinal health and can be a promising alternative to antibiotics in piglets diet.
\end{abstract}

Keywords: Bacillus subtilis, Piglets, Growth performance, Intestinal function, Serum parameters, Colonic microbiota

\section{Introduction}

Environmental and nutritional stressors affect health and growth performance in all life phases of livestock production. Antibiotics have been included in feed formulations as growth promoter to improve feed efficiency and reduce pathogen infections for more than 50 years (Dibner and Richards 2005). However, there is increasing evidence that antibiotic abuse leads to bacterial resistance, which poses a huge risk for public health (Martin

\footnotetext{
*Correspondence: zjsnkyxzw@163.com

${ }^{1}$ Institute of Animal Husbandry and Veterinary Science, Zhejiang Academy of Agricultural Sciences, Hangzhou 310021, Zhejiang, China Full list of author information is available at the end of the article
}

et al. 2015). The European Union banned antibiotics as growth promoter in 2006 and China will also prohibit prophylactic use of antibiotics in feed in 2020. Probiotics are considered one of potential alternative to antibiotics. The supplementation of probiotics have been widely reported to improve growth performance and intestinal immunity, enhance the intestinal epithelial barrier, and suppress pathogens (Resta-Lenert and Barrett 2006; Bermudez-Brito et al. 2012; Liao and Nyachoti 2017). Bacillus subtilis is "metabolically dormant and as close to indestructible as any cell found on earth; nonetheless, the spore retains the ability to revive almost immediately when nutrients return to the environment" (Driks 2002). Generally, B. subtilis is used in the spore form and can 
maintain stability in storage and be resistant to unfavorable environments during transit through the gastrointestinal tract. Numerous studies have demonstrated the beneficial effects of $B$. subtilis without safety concerns (Guo et al. 2006; Lee et al. 2014; Zhou et al. 2015). While not all strains are equally resistant to the environment in the gastrointestinal tract, and the pharmabiotic action of probiotics (including Bacillus spp.) from different strains is multi-factorial and strain-specific, some strains are more beneficial to the host than others (Weichselbaum 2009). In our previous research, we had demonstrated a strain of B. subtilis which improved intestinal function, reduced inflammation and developed microflora in LPSinduced acute inflammation rat (Deng et al. 2017). In the present study, we further evaluated the effect of B. subtilis on growth performance, serum parameters, digestive enzymes, intestinal morphology, and colonic microbiota in piglets.

\section{Materials and methods}

\section{Source of probiotics}

The B. subtilis bacterial strain (BF7658, CGMCC 1.240) was purchased from the China General Microbiological Culture Collection Center (CGMCC) and used in this study after being cultivated in Institute of Plant Protection and Microbiology, Zhejiang Academy of Agricultural Sciences. The strain containing $B$. subtilis at least $1 \times 10^{10} \mathrm{CFU} / \mathrm{g}$.

\section{Animals, diets, and experimental design}

A total of 72 piglets of approximately 45 days of age and $14.06 \pm 1.80 \mathrm{~kg}$ body weight (BW) (36 barrows and 36 gilts, Duroc $\times$ Large White $\times$ Landrace) were used in a 28-day feeding trail. All piglets were weighed and randomly assigned to three treatments and each treatment included four pens with six piglets/pen (three barrows and three gilts). The three treatments were: basal diet (control group, CTR), basal diet supplied with $40 \mathrm{mg} / \mathrm{kg}$ kitasamycin and $75 \mathrm{mg} / \mathrm{kg}$ chlorotetracycline (antibiotic group, ABT), and basal diet supplied with $0.1 \%$ B. subtilis (probiotic group, PBT). The basal diets were corn and soybean-based diets offered in meal form and were formulated to meet the specifications of growing piglets (Table 1).

Piglets were housed in pens with separated feeders and automatic, stainless steel, nipple drinkers. Feed and water were available ad libitum throughout the experimental period. A combination of daylight and artificial light was used and room temperature was controlled at 24 to $26^{\circ} \mathrm{C}$. Piglets were observed at least twice per day for health status, and routine veterinary inspections were performed with additional visits upon the detection of ailments.
Table 1 Composition and nutrition levels of the basal diet (as-fed basis)

\begin{tabular}{ll}
\hline Items & Content (\%) \\
\hline Ingredient & \\
Maize & 45 \\
Extrusion full fat soybean & 13 \\
Soybean meal & 15 \\
Extrusion maize & 20 \\
Fish meal & 3 \\
Dicalcium phosphate & 1.1 \\
Calcium carbonate & 0.9 \\
Sodium chloride & 0.3 \\
Premix & 1.7 \\
Nutrient levels & \\
Crude protein & 18.56 \\
DE (MJ/kg) & 14.15 \\
Crude fiber & 2.72 \\
Ether extract & 4.39 \\
Calcium & 0.8 \\
Total phosphorous & 0.72 \\
Digestible lysine & 1.09 \\
Digestible methionine & 0.29 \\
Digestible threonine & 0.76 \\
Digestible tryptophan & 0.21 \\
\hline DE &
\end{tabular}

$D E$ digestible energy

a Premix provided the following per kilogram of basal diet: $\mathrm{Cu} 20 \mathrm{mg}, \mathrm{Zn} 70 \mathrm{mg}$, Fe $100 \mathrm{mg}, \mathrm{Mn} 40 \mathrm{mg}$, Se $0.3 \mathrm{mg}, \mathrm{I} 0.4 \mathrm{mg}$. Vitamin A $7500 \mathrm{IU}$, vitamin D3 $750 \mathrm{IU}$, vitamin E $25 \mathrm{IU}$, vitamin $\mathrm{K} 32.0 \mathrm{mg}$, vitamin B1 $1.88 \mathrm{mg}$, vitamin B2 $3.75 \mathrm{mg}$, vitamin B6 $2.19 \mathrm{mg}$, vitamin B12 $0.025 \mathrm{mg}$, nicotinic acid $25 \mathrm{mg}$, D-pantothenic acid $15.6 \mathrm{mg}$, folic acid $2.0 \mathrm{mg}$, biotin $0.19 \mathrm{mg}$

${ }^{b}$ Nutrient levels were calculated values

Piglets were weighted individually on day 0 and 28 , and feed consumption was measured to calculate average daily gain (ADG), average daily feed intake (ADFI), and feed:gain ratio (F:G). On day 28 , three healthy barrows and three healthy gilts from each treatment were selected to be euthanized with Zoletil (15 mg tiletamine/ $\mathrm{kg} \mathrm{BW,}$ $15 \mathrm{mg}$ zolazepam $/ \mathrm{kg} \mathrm{BW}$, intramuscular injection) and bled by exsanguinations.

\section{Sample collection}

Blood samples were collected from the anterior vena into Eppendorf tubes. Serum samples were obtained after centrifugation at $3000 \mathrm{rpm}$ for $10 \mathrm{~min}$ at $4{ }^{\circ} \mathrm{C}$, and was stored at $-80{ }^{\circ} \mathrm{C}$ until analysis. Samples of the proximal duodenum, middle jejunum, and distal ileum were collected and washed with ice-cold physiological saline immediately. For histology, tissue samples were placed into $10 \%(\mathrm{v} / \mathrm{v})$ neutral buffered formalin. For enzyme activity analysis, mucosal samples were scraped off each intestinal segment onto a glass slide and snap frozen into liquid nitrogen. Colonic digesta were collected into 
Eppendorf tubes and immediately snap frozen in liquid nitrogen for $16 \mathrm{~S}$ high-throughput sequencing.

\section{Intestinal morphology}

After fixation in neutral buffered formalin for $24 \mathrm{~h}$, tissues of each intestine segment were embedded in paraffin. A section of $0.5 \mathrm{~cm}$ thickness was stained with hematoxylin and eosin (HE) to analyze villus height and crypt depth. Images were acquired using an Olympus DP-71 digital camera (OLYMPUS Corporation, Shinjuku, Tokyo, Japan). Mean villous height and mean crypt depth were determined using an image processing system equipped with Image-ProPlus 5.0 (Media Cybernetics, Maryland, USA). The detail method was based on previously published methods (Lee et al. 2014).

\section{Serum biochemical parameters and mucosal digestive enzymes}

The concentration of serum biochemical parameters: glucose, triglyceride (TG), total cholesterol (TC), high density fatty acid (HDLC) and low density fatty acid (LDLC) were measured by commercial assay kits (Nanjing Jiancheng Bio-Engineering Institute, Nanjing, China) according to the manufacturer's instructions (Ding et al. 2020).

Approximately $0.5 \mathrm{~g}$ of frozen intestinal mucosal samples were homogenized in $4.5 \mathrm{~mL}$ ice-cold $0.9 \% \mathrm{NaCl}$ solution by a homogenizer. Then the homogenates were centrifuged at $4{ }^{\circ} \mathrm{C}$ for $15 \mathrm{~min}$ at $4000 \mathrm{rpm}$ to obtain the supernatant. The activities of digestive enzymes (trypsase, lipase, amylase, sucrase, lactase, and maltase) in the supernatants were measured by commercial assay kits (Nanjing Jiancheng Bio-Engineering Institute, Nanjing, China) according to the manufacturer's instructions (Rajput et al. 2013; Huo et al. 2017).

\section{High-throughput sequencing}

Total DNA from colon digesta was extracted using a MicroElute Genomic DNA kit (D3096-01, Omega, Inc., USA). The V3-V4 fragment of $16 \mathrm{~S}$ rRNA was amplified using the total DNA as a template and the conserved primers are 319F (5'-ACTCCTACGGGAGGC AGCAG-3) and 806R (5'-GGACTACHVGG GTWTCT AAT-3) (He et al. 2019). The specific steps are shown in Additional file 1. All sequences generated in this study have been submitted to the NCBI Sequence Read Archive (https://www.ncbi.nlm.nih.gov/sar) under accession number SRA: PRJNA665361.

\section{Statistical analyses}

The analyses of growth performance, serum parameters, digestive enzymes, and intestinal morphology, relative abundance of phylum and species between groups were performed by one-way ANOVA with line segment detector (LSD) using the SPSS 22.0 software (SPSS Inc., Chicago, IL, USA). Alpha diversity and taxonomic community assessments were performed using Qiime 1.7.0. Principal coordinates analysis (PCoA) and nonmetric multidimensional scale analysis (NMDS) plots were generated using weighted UniFrac metrics. The experiment unit of growth performance is pen and experiment unit of other index is individual animal. All data are shown as the mean \pm standard error of mean (SEM). Statistical significance was considered at $P<0.05$.

\section{Results}

\section{Growth performance}

Supplementation of antibiotics increased final BW and ADG, and decreased F:G $(P<0.05$; Table 2). Piglets supplemented with $B$. subtilis also showed positive effects in growth performance, with increased final BW and ADG, as compared to the CTR group $(P<0.05)$. No significant differences were observed between the $\mathrm{ABT}$ and $\mathrm{PBT}$ group $(P>0.05)$.

\section{Serum parameters}

The analysis of serum parameters showed that antibiotic treatment markedly increased serum triglyceride and cholesterol $(P<0.05$, Table 3). B. subtilis supplementation increased serum glucose and triglyceride $(P<0.05)$, while dietary supplementation of antibiotic or probiotics had no effect on serum HDLC and LDLC levels $(P>0.05)$.

\section{Mucosal digestive enzymes}

Activity of amylase and lipase in the ileum were significantly increased in both ABT and PBT groups $(P<0.05)$ (Table 4). In addition, dietary supplementation of $B$. subtilis

Table 2 Effects of dietary B. subtilis supplementation on growth performance of piglets

\begin{tabular}{lcclll}
\hline Items & $\mathbf{C T R}^{\mathbf{c}}$ & $\mathbf{A B T}^{\mathbf{d}}$ & $\mathbf{P B T}^{\mathbf{e}}$ & $\mathbf{S E M}^{\mathbf{f}}$ & $\boldsymbol{P}^{\text {-value }}$ \\
\hline Initial body weight $(\mathrm{kg})$ & 14.07 & 14.05 & 14.07 & 0.005 & 0.14 \\
Final body weight $(\mathrm{kg})$ & $28.27^{\mathrm{b}}$ & $31.22^{\mathrm{a}}$ & $31.15^{\mathrm{a}}$ & 0.53 & 0.002 \\
ADG (kg) & $0.51^{\mathrm{b}}$ & $0.61^{\mathrm{a}}$ & $0.61^{\mathrm{a}}$ & 0.12 & 0.002 \\
ADFI (kg) & 1.00 & 1.11 & 1.13 & 0.03 & 0.08 \\
F:G & $1.97^{\mathrm{a}}$ & $1.81^{\mathrm{b}}$ & $1.84^{\mathrm{a}} \mathrm{b}$ & 0.03 & 0.04 \\
\hline
\end{tabular}

$A D G$ average daily gain, $A D F I$ average daily feed intake, $F: G$ feed:gain ratio

a, b Value within a row with different superscripts were considered to be significant when $P<0.05$ ( $n=4$ per treatment)

c $C T R$ control group (basal diet); the same as below

d $A B T$ antibiotic group (basal diet supplied with $40 \mathrm{mg} / \mathrm{kg}$ kitasamycin and $75 \mathrm{mg} / \mathrm{kg}$ chlorotetracycline); the same as below

e PBT probiotic group (basal diet supplied with $0.1 \%$ B. subtilis); the same as below

f SEM standard error of the mean; the same as below 
Table 3 Effects of dietary B. subtilis supplementation on serum parameters of piglets

\begin{tabular}{llllll}
\hline Items $(\mathbf{m m o l} / \mathbf{L})$ & CTR & ABT & PBT & SEM & $P$-value \\
\hline Glucose & $5.56^{\mathrm{b}}$ & $6.48^{\mathrm{a}}$ & $8.57^{\mathrm{a}}$ & 0.51 & 0.005 \\
Triglyceride & $0.27^{\mathrm{b}}$ & $0.47^{\mathrm{a}}$ & $0.48^{\mathrm{a}}$ & 0.04 & 0.009 \\
Cholesterol & $2.93^{\mathrm{b}}$ & $3.65^{\mathrm{a}}$ & $3.00^{\mathrm{b}}$ & 0.22 & 0.035 \\
HDLC & 1.03 & 0.99 & 1.12 & 0.07 & 0.15 \\
LDLC & 1.36 & 1.47 & 1.46 & 0.09 & 0.67 \\
\hline
\end{tabular}

$H D L C$ high density fatty acid, $L D L C$ low density fatty acid

$a, b$ Value within a row with different superscripts were considered to be significant when $P<0.05$ ( $n=6$ per treatment), the same as Tables 4,5

also improved lactase and maltase activity in the ileum, as compared to both the CTR and ABT groups $(P<0.05)$.
Intestinal morphology

The villus height/crypt depth ratio $(\mathrm{V} / \mathrm{C})$ in ileum markedly increase with dietary supplementation of antibiotics or B. subtilis. Also, villus height was significantly improved in the ileum of piglets in the PBT group as compared to CTR group $(P<0.05$, Table 5$)$.

\section{Colonic microbiota}

Dietary supplementation of $B$. subtilis significantly increased microbiota and the Chao-1 index $(P<0.05)$, and tended to increase the Shannon index $(P=0.056)$ and the Simpson index $(P=0.088)$ as compared to the ABT group (Fig. 1). No differences were observed between the CTR and PBT groups $(P>0.05)$.

Table 4 Effects of dietary B. subtilis supplementation on mucosal digestive enzyme of piglets

\begin{tabular}{|c|c|c|c|c|c|c|}
\hline & Items & CTR & ABT & PBT & SEM & $P$-value \\
\hline \multirow[t]{6}{*}{ Duodenum } & Trypsase (U/mg protein) & 49.99 & 56.71 & 66.09 & 4.03 & 0.11 \\
\hline & Lipase (U/g protein) & 1.93 & 1.85 & 2.54 & 0.17 & 0.20 \\
\hline & Amylase (U/mg protein) & 0.61 & 0.54 & 1.25 & 0.12 & 0.05 \\
\hline & Sucrase (U/mg protein) & 8.64 & 7.89 & 7.70 & 0.69 & 0.84 \\
\hline & Lactase (U/mg protein) & 11.56 & 11.83 & 10.43 & 0.73 & 0.39 \\
\hline & Maltase (U/mg protein) & 169.30 & 154.25 & 169.82 & 11.92 & 0.29 \\
\hline \multirow[t]{6}{*}{ Jejunum } & Trypsase (U/mg protein) & 85.28 & 99.40 & 102.95 & 7.79 & 0.56 \\
\hline & Lipase (U/g protein) & 3.40 & 3.69 & 3.64 & 0.24 & 0.76 \\
\hline & Amylase (U/mg protein) & 1.36 & 1.30 & 1.40 & 0.09 & 0.89 \\
\hline & Sucrase (U/mg protein) & 80.59 & 74.47 & 70.10 & 6.38 & 0.82 \\
\hline & Lactase (U/mg protein) & 20.22 & 26.26 & 26.88 & 1.81 & 0.14 \\
\hline & Maltase (U/mg protein) & 165.06 & 177.27 & 153.61 & 11.17 & 0.29 \\
\hline \multirow[t]{6}{*}{ lleum } & Trypsase (U/mg protein) & 216.71 & 162.73 & 222.37 & 14.79 & 0.16 \\
\hline & Lipase (U/g protein) & $3.71^{b}$ & $5.32^{\mathrm{a}}$ & $4.92^{\mathrm{a}}$ & 0.4 & 0.004 \\
\hline & Amylase (U/mg protein) & $0.44^{b}$ & $1.66^{\mathrm{a}}$ & $2.25^{\mathrm{a}}$ & 0.23 & 0.014 \\
\hline & Sucrase (U/mg protein) & 65.04 & 64.86 & 74.56 & 6.1 & 0.85 \\
\hline & Lactase (U/mg protein) & $4.08^{b}$ & $4.21^{b}$ & $6.19^{a}$ & 0.4 & 0.005 \\
\hline & Maltase (U/mg protein) & $111.94^{c}$ & $142.55^{b}$ & $185.51^{\mathrm{a}}$ & 11.88 & 0.002 \\
\hline
\end{tabular}

Table 5 Effects of dietary B. subtilis supplementation on intestinal morphology of piglets

\begin{tabular}{|c|c|c|c|c|c|c|}
\hline & Items & CTR & ABT & PBT & SEM & $P$-value \\
\hline \multirow[t]{3}{*}{ Duodenum } & Villus height & 197.07 & 180.33 & 197.82 & 11.64 & 0.49 \\
\hline & Crypt depth & 230.76 & 216.29 & 203.30 & 13.28 & 0.53 \\
\hline & $\mathrm{V} / \mathrm{C}$ & 0.92 & 0.84 & 0.98 & 0.06 & 0.16 \\
\hline \multirow[t]{3}{*}{ Jejunum } & Villus height & 169.19 & 156.93 & 170.22 & 10.25 & 0.78 \\
\hline & Crypt depth & 154.34 & 144.36 & 163.07 & 9.55 & 0.46 \\
\hline & $\mathrm{V} / \mathrm{C}$ & 1.11 & 1.12 & 1.06 & 0.07 & 0.71 \\
\hline \multirow[t]{3}{*}{ Ileum } & Villus height & $106.34^{b}$ & $130.55^{a, b}$ & $141.26^{\mathrm{a}}$ & 9.27 & 0.04 \\
\hline & Crypt depth & 148.59 & 129.42 & 140.11 & 9.8 & 0.41 \\
\hline & $\mathrm{V} / \mathrm{C}$ & $0.74^{b}$ & $1.07^{a}$ & $1.04^{a}$ & 0.08 & 0.04 \\
\hline
\end{tabular}

V/C villus height/crypt depth ratio 

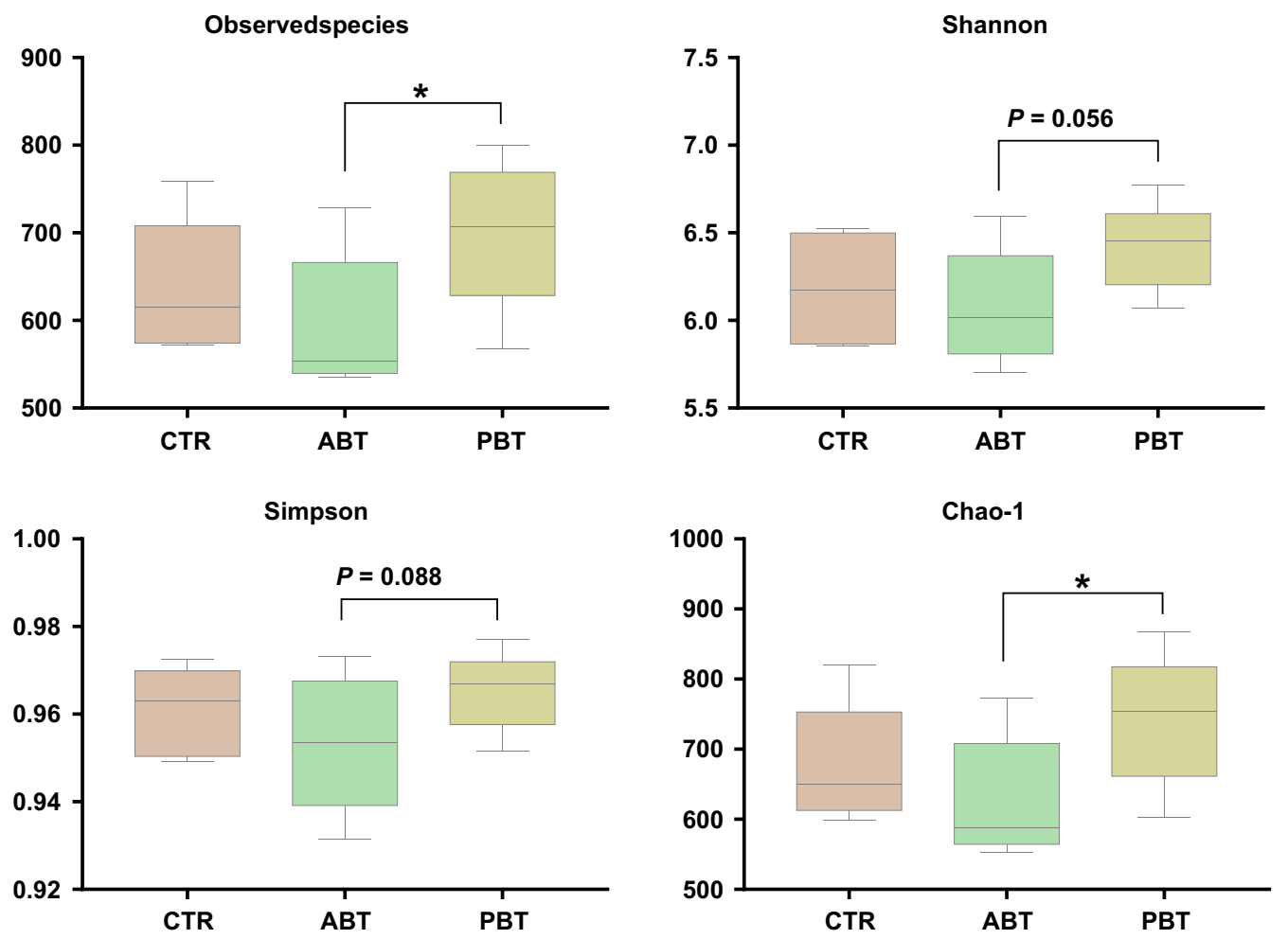

Fig. 1 Effects of dietary B. subtilis supplementation on colonic microbial community diversity of piglets. Data are expressed as mean \pm SEM. * Were considered to be significant when $\mathrm{P}<0.05$

To describe the gut microbiota of piglets, distance matrices were calculated by weighted UniFrac and visualized via PCoA and NMDS (Fig. 2). Piglets on the same feed tended to cluster together and were separate from other groups. PBT samples were mostly separated from ABT samples.

Phylum distributions show that the colonic microbiomes were dominated by Firmicutes and Bacteroidetes, which comprised $90 \%$ of the total bacteria in piglets (Fig. 3). Dietary supplementation of antibiotics showed limited effects on these two bacterial populations (Firmicutes CTR $55.50 \%$ vs ABT $62.29 \%$, Bacteroidetes CTR $38.84 \%$ vs ABT 30.47\%). Dietary supplementation of B. subtilis increased Firmicutes (CTR $55.50 \%$ vs PBT $67.54 \%, P<0.05)$, and tended to decrease the abundance of Bacteroidetes (CTR $38.84 \%$ vs PBT $27.42 \%, P=0.059$ ).

At species level, we focused attention on Lactobacillus spp. (a), Clostridium spp. (b), and E. coli (c) within the top 25 species (Fig. 4). The results showed that dietary supplementation of antibiotics markedly increased the abundance of $L$. johnsonii $(P<0.05)$, and tended to increase the abundance of $L$. amylovorus $(\mathrm{P}=0.062)$ and $L$. reuteri $(P=0.06)$. Antibiotics also tended to increase the abundance of $E$. coli, as compared to the CTR group $(P=0.057)$. Dietary supplementation of $B$. subtilis significantly increased the level of L. johnsonii and $L$. reuteri $(P<0.05)$ and tended to increase $L$. amylovorus $(P=0.06)$. Moreover, B. subtilis decreased $E$. coli, as compared to both the CTR and ABT groups $(P<0.05)$. No differences were noted in the abundance of the three Clostridium spp. between all groups.

\section{Discussion}

Bacillus subtilis is one of most commonly used probiotics in livestock feed, but previous studies have indicated contrasting results in livestock production, which might be due to different hosts or even the use of probiotics of different species (Kritas and Morrison 2005; Lee et al. 2014). Our previous study isolated a strain of B. subtilis and demonstrated its effectiveness in LPS-induced acute inflammation in rats. In the present study, B. subtilis was used in piglets to determine whether it could effectively replace antibiotics.

Improved growth performance in piglets supplemented with B. subtilis or antibiotics was observed in the present study, and antibiotics showed a higher feed efficiency. The results agreed with Lee et al's (2014) research, who reported a linear improvement in both ADG and ADFI with increasing $B$. subtilis in the $\operatorname{diet}(0.15,0.3$, and $0.45 \mathrm{mg} / \mathrm{kg}$ ). Gracia et al. (2004) also found that adding 

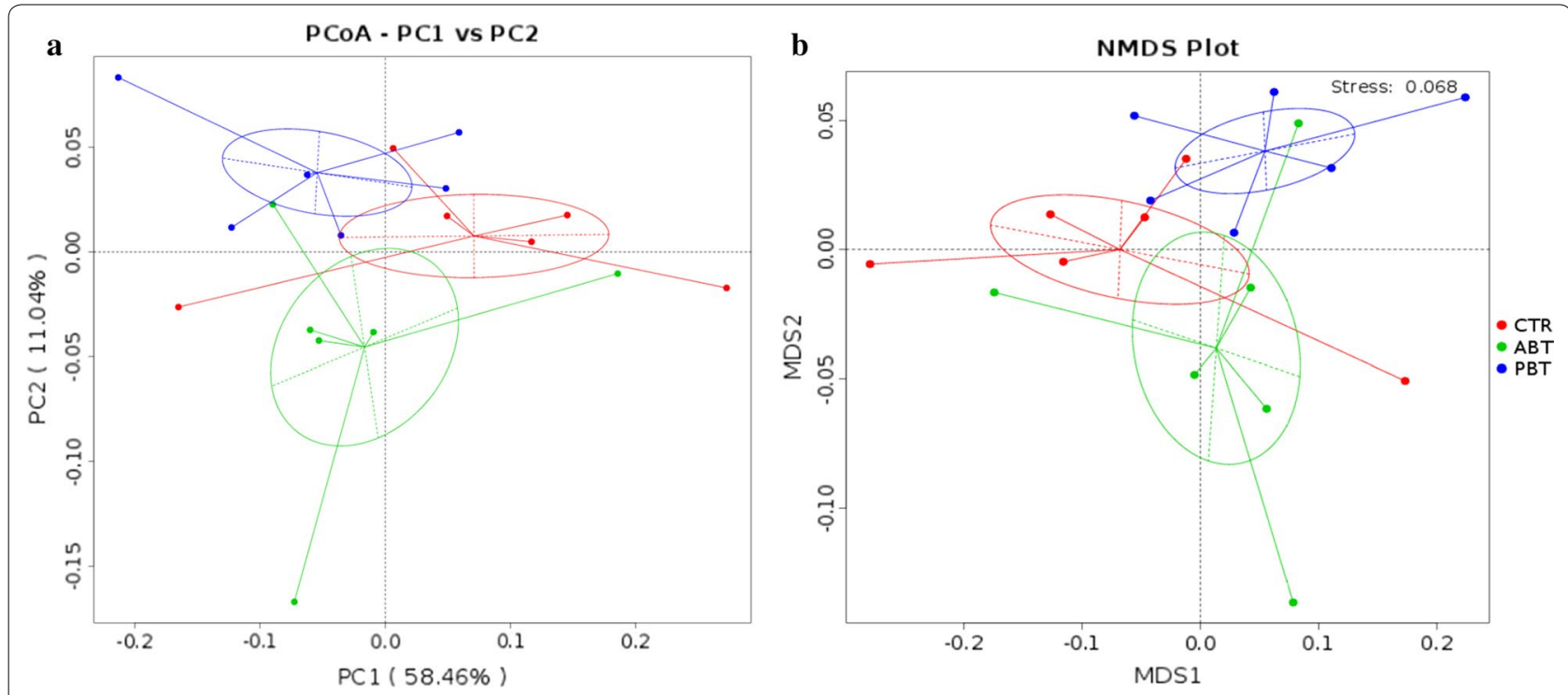

Fig. 2 Effects of dietary B. subtilis supplementation on colonic microbial community structures of piglets. a Represents PCoA analyze based on the weighted UniFrac distance matrixes, $\mathbf{b}$ represents NMDS analyze based on the weighted UniFrac distance matrixes

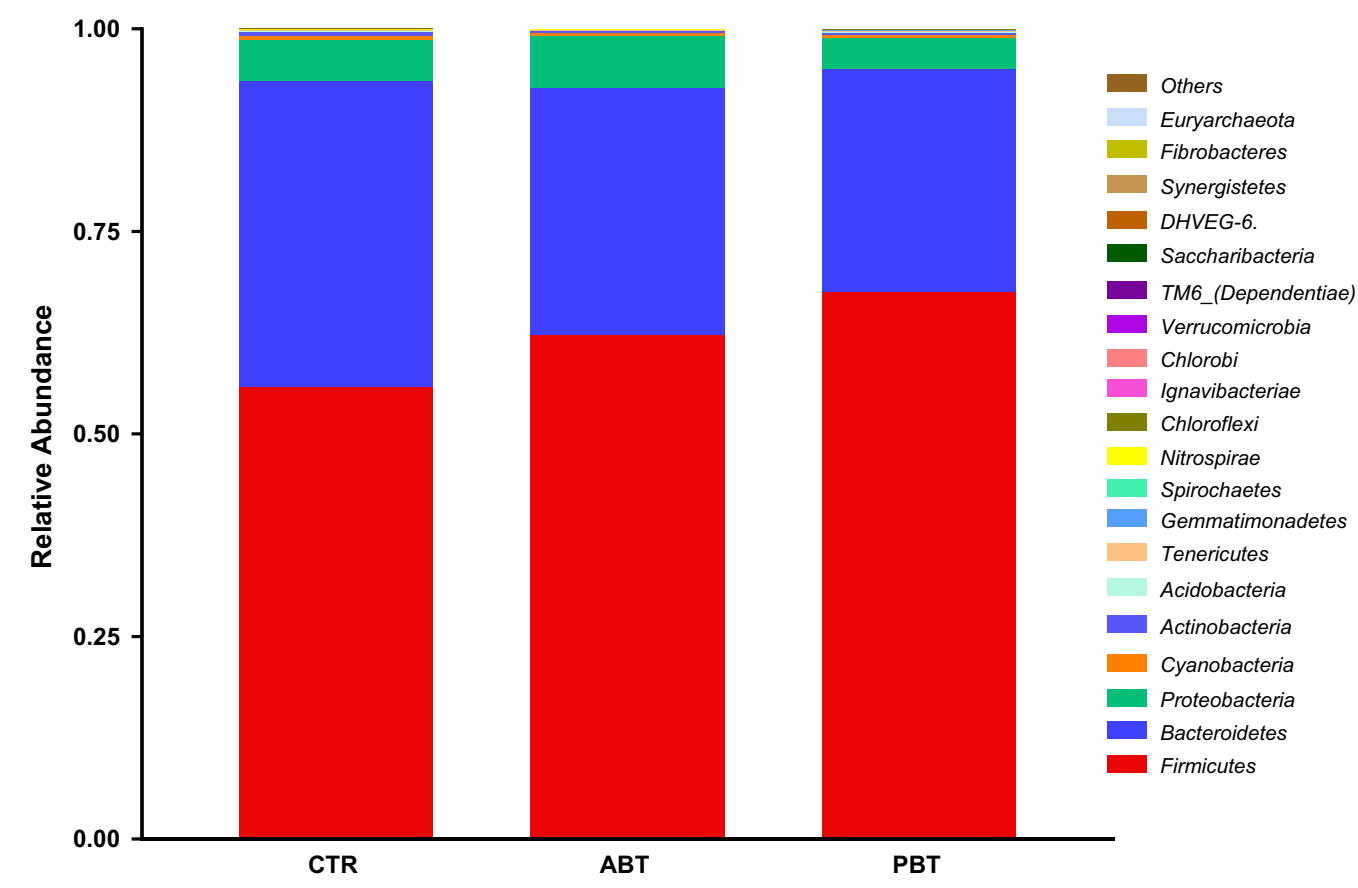

Fig. 3 Effects of dietary B. subtilis supplementation on colonic microbiota composition at phylum level with the relative abundance within the top 20 of piglets

$0.04 \%$ of a probiotic mixture including $B$. subtilis and $B$. licheniformis could benefit ADG and ADFI during the pre-starter period and the overall pre-starter-finishing period. There are contradicting results, however. Kritas and morrison's (2005) research failed to demonstrate any effects of $B$. subtilis and $B$. licheniformis inclusion on growth performance in piglets. Jørgensen et al. (2016) even noted that feeding $400 \mathrm{mg} / \mathrm{kg}$ of a Bacillusbased probiotic decreased ADG and increased F:G in the grower period. The variability of results on growth 


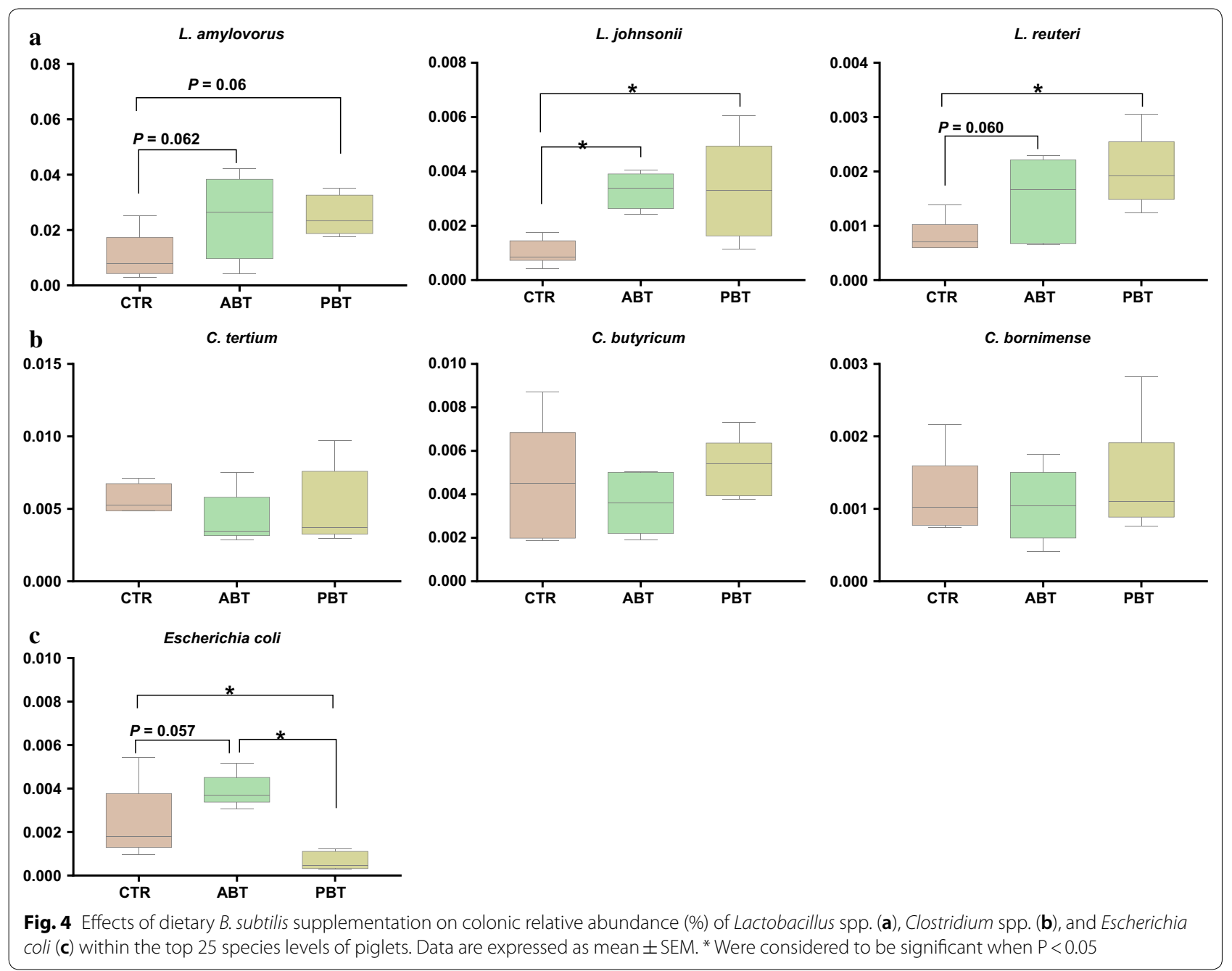

performance may be associated with dose level, animal age, strain source, host health status or even the administration strategies (Wang et al. 2009; Lee et al. 2014).

We measured the serum parameters including glucose, TG, TC, HDLC, and LDLC to evaluate the nutrition levels in piglets. Significant improvements in glucose and TG were observed in piglets with supplementary $B$. subtilis. Ding et al. (2020) also demonstrated that basal diets supplemented with $0.05 \%$ B. subtilis had higher plasma glucose and triglycerides on day 28 and day 42 , and higher $\alpha$-amylase and LDLC on day 28 in nursery piglets. Rajput et al.s (2013) research showed that B. subtilis decreased the content of TG in broilers. In mice fed high fat diets, decreased lipid profiles were also noted by Zouari et al. (2016) when B. subtilis SPB1 was included in the feed. The differences may be due to energy intake levels and growth stage. In the starter period of pig growth, especially during weaning, glucose and TG are major sources of energy but energy intake commonly cannot meet the requirement (Bruininx et al. 2001). In this case, the glucose and TG provided by B. subtilis would be beneficial to fast and healthy growth of piglets.

Digestive enzymes are important to hydrolyze food into smaller and absorbable components which directly influence the nutrient digestibility and growth performance. Intestinal, disaccharidase-specific activities are also used to measure intestinal health and maturity in response to dietary factors (Pi et al. 2014). In the present study, dietary supplementation of $B$. subtilis improved tryptase activity in the duodenum and lipase, amylase, lactase, and maltase activity in the ileum. The results indicated that B. subtilis might support the action of lipid, protein, and carbohydrate metabolism and promote the maturity of mucosa in piglets. Our findings are in agreement with Huo et al.s (2017) research, who illustrated that $0.1 \% B$. subtilis Z-27 markedly increased the activity of acid protease, lipase, $\alpha$-amylase, and cellulose in the duodenum, jejunum and ileum of weaned piglets. Similarly, Rajput 
et al. (2012) reported that dietary supplementation of $1 \times 10^{8} \mathrm{CFU} / \mathrm{kg} \mathrm{B}$. subtilis for 35 days increased amylase and trypsin activity in Shaoxin duck.

Small intestinal morphology is a crucial factor in the maintenance of normal intestinal functions. In the current study, dietary $B$. subtilis markedly increased villus height in the ileum and tended to increase $\mathrm{V} / \mathrm{C}$ in the ileum. The positive changes in intestinal morphology indicated improved growth and a better assimilation in the gut. We did not measure nutrient digestibility, but the results of serum glucose, lipid metabolites, and digestive enzymes support the speculation. The finding is in agreement with Lee et al. (2014) who noted a positive effect on villus height and $\mathrm{V} / \mathrm{C}$ in the duodenum, jejunum, and ileum in pigs fed with $0.45 \%$ B. subtilis LS $1-2$. Kim et al. (2012) also demonstrated that supplementation of a multi-microbe probiotic product containing $B$. subtilis in broiler diets improved villus height and $\mathrm{V} / \mathrm{C}$ in the duodenum and ileum at day 35 . Other studies have demonstrated that the intestinal morphology was not altered by B. subtilis. Choi et al. (2011) demonstrated that multimicrobe probiotics containing $B$. subtilis showed limited effects on villus height and crypt depth in different intestinal segments. In $E$. coli K88-challenged pigs, dietary supplementation with a B. subtilis-based microbial also failed to improve intestinal morphology (Bhandari et al. 2008). The different results may due to the supplementation level and healthy status of the host.

The bacterial composition and diversity of gut microbes is very dynamic and can be influenced by several factors. Bhandari et al. (2008) noted that B. subtilis markedly increased bacterial richness and divty in $E$. coli K88-challenged piglets. Another study by $\mathrm{Hu}$ et al. (2014) revealed that weaned piglets treated with $B$. subtilis $\mathrm{KN}-42$ showed the highest bacterial diversity by measuring the number of identifiable DGGE bands. Our recent research also found that $B$. subtilis increased the microbiota and Chao-1 index in rats (Deng et al. 2017). The increased bacterial diversity means more stable bacterial communities which increase the host's ability to respond to perturbations (McCann 2000). Firmicutes and Bacteroidetes are two dominant bacterial phyla in pigs and humans and are linked processes impacting host health, such as fat metabolism and carbohydrate fermentation (Lee et al. 2009). Cui et al. (2013) noted that dietary of B. subtilis increased the ratio of Firmicutes to Bacteroidetes in a long term study of pigs from 10 to $110 \mathrm{~kg}$. In the present study, we also observed an increase of the abundance of Firmicutes and a decrease in Bacteroidetes in B. subtilis-treated piglets. The alteration of the Firmicutes/Bacteroidetes ratio suggests that B. subtilis might promote the metabolic activities and fermentation of complex plant-based diets and tend to deposit fat (Cui et al. 2013). A study by Guo et al. (2008) also revealed that a higher Firmicutes/Bacteroidetes ratio normally corresponds to an increased BW, which is consistent with our study. The ratio of Firmicutes to Bacteroidetes showed a strong negative correlation to pathogens in the gut and a positive correlation to intestinal short chain fatty acids (Molist et al. 2012), which might reduce infection and responses to unfavorable environments (Mulder et al. 2009).

Lactobacillus spp. are considered as beneficial microorganisms that increase intestinal function, improve immune system, and modify intestinal microflora, thereby improving overall health of the host. In the present study, B. subtilis showed a positive effect on the proliferation of the three Lactobacillus spp. including $L$. johnsonii, L. reuteri, and L. amylovorus. The result was similar to those of previous studies. Guo et al. (2006) reported that B. subtilis MA139 with $2.2 \times 10^{5} \mathrm{CFU} / \mathrm{g}$ supplementation for piglets to 28 days markedly increased Lactobacillus spp. in the feces. A previous study by Wang et al. (2019) also showed that $0.1 \%$ B. subtilis $\left(1 \times 10^{9} \mathrm{CFU} / \mathrm{kg}\right)$ promoted the proliferation of $\mathrm{Lac}$ tobacillus in feces of piglets, while the effect was absence in the lower viable count $\left(1 \times 10^{8} \mathrm{CFU} / \mathrm{kg}\right)$. We also noted that B. subtilis suppressed the growth of Escherichia coli. E. coli is a major pathogen causing diarrhea in piglets. Decreased E. coli suggested that B. subtilis could effectively prevent diarrhea in piglets (Fairbrother et al. 2005). The results concur with Tsukahara et al.s (2013) study, who found that oral administration of $B$. subtilis DB9011 decreased growth of Shiga toxin 2e-producing $E$. coli in piglets. Another study by Giang et al. (2011) also revealed that dietary supplementation of Bacillus showed positive effects on decreasing $E$. coli counts in feces and, combined with Saccharomyces and lactic acid bacteria, the effect was reinforced. The potential mechanism of antimicrobial effects might be associated with the metabolites produced by $B$. subtilis, such as lipopeptides and aminocumaim A.

Kitasamycin and chlorotetracycline were used as an antibiotic combination to evaluate the B. subtilis here in used. The results revealed that supplementation with B. subtilis showed similar effects to antibiotics in most indexes including growth performance, intestinal morphology, or even better on some aspects, such as digestive enzyme activity. The use of probiotics as an alternative to antibiotics was also shown in previous studies by using single or multi-probiotic products (Shen et al. 2009; Choi et al. 2011). As a growth promoter, it remains controversial as to whether probiotics would be effective as antibiotics. Afsharmanesh et al. (2013) noted that growth performance was significantly lower in broiler chickens fed $8 \times 10^{5} \mathrm{CFU} / \mathrm{kg}$ B. subtilis 
in comparison to antibiotics, even though probiotics produced a better intestinal morphology. The reasons for this are complex, and may be related to host health state, strain of probiotic, dosage of antibiotic, and the management environment. In the present study, room temperature was about $24{ }^{\circ} \mathrm{C}$ and initial BW was about $14 \mathrm{~kg}$, which suggested a favorable environment for growth and strong resistance to disease, which might mask the effects of the antibiotic. Intestinally, we noted that antibiotics and probiotics showed different effects on gut microbes. Although both antibiotics and B. subtilis increased Lactobacillus spp., antibiotics decreased colonic bacterial diversity and increased E. coli, as compared to the probiotic group. Similar results were also shown in Dethlefsen et al's (2008) study, who found that 5 days of treatment with Ciprofloxacin decreased taxonomic richness within days of initial exposure. Looft et al. (2012) observed that swine fed ASP250 containing chlortetracycline, sulfamethazine, and penicillin increased $E$. coli population at 14 days, showing a 20- to 100-fold greater E. coli abundance in medicated than non-medicated swine. The different action on gut microbes could be an advantage of probiotics.

In conclusion, this study demonstrated that dietary of B. subtilis was effective in improving growth performance, digestive enzyme activity, and intestinal morphology. Furthermore, B. subtilis also increased bacterial diversity, increased Lactobacillus spp., and decreased $E$. coli in piglets. These results suggest that $B$. subtilis is a promising alternative to antibiotics in piglet feed. However we should note that the piglets used in this study is relatively big but not just weaned, more experiments with different conditions such as different growth periods or different feeding environment need to be carried out to verify the efficiency of $B$. subtilis. And the underlying mechanisms of how this $B$. subtilis strain works should be further assessed by analyzing its metabolites.

\section{Supplementary information}

Supplementary information accompanies this paper at https://doi. org/10.1186/s13568-020-01150-z.

Additional file 1. Methods for Amplification of $\mathrm{V} 3-\mathrm{V} 4$ region

\begin{abstract}
Abbreviations
CTR: Control group; ABT: Antibiotic group; PBT: Probiotic group; B. subtilis: Bacillus subtilis; E. coli: Escherichia coli; F:G: Feed:gain ratio; BW: Body weight; ADG: Average daily gain; ADFI: Average daily feed intake; HE: Hematoxylin and eosin; TG: Triglyceride; V/C: Villus height:crypt depth ratio; PCoA: Principal coordinates analysis; NMDS: Nonmetric multidimensional scale analysis.
\end{abstract}

Acknowledgements

Not applicable.

\section{Authors' contributions}

$B D$ and $Z W X$ designed the protocol of the study. BD, JW, CZ performed the experimental. XHL and XMM performed the statistical analysis. BD, JW and ZWX wrote and modified the manuscript. All authors read and approved the final manuscript.

\section{Funding}

This study was supported by grants from the Key Research Project of Zhejiang province (Grant No. 2018C02044) and Modern Agro-Industry Technology Research System of China (CARS-35).

\section{Availability of data and materials}

The datasets used or analyzed during the current study are available from the corresponding author on reasonable request.

\section{Ethics approval and consent to participate}

Animal studies were performed in accordance with the guidelines of Zhejiang Farm Animal Welfare Council of China and approved by the Ethics Committee of Zhejiang Academy of Agricultural Sciences.

\section{Consent for publication}

Not applicable.

\section{Competing interests}

The authors declare that they have no competing interests.

\section{Author details}

${ }^{1}$ Institute of Animal Husbandry and Veterinary Science, Zhejiang Academy of Agricultural Sciences, Hangzhou 310021, Zhejiang, China. ${ }^{2}$ Institute of Plant Protection and Microbiology, Zhejiang Academy of Agricultural Sciences, Hangzhou 310021, Zhejiang, China. ${ }^{3}$ Hangzhou Zhengxing Animal Husbandry Co., Ltd., Hangzhou 311301, Zhejiang, China.

Received: 27 September 2020 Accepted: 21 November 2020

Published online: 02 December 2020

\section{References}

Afsharmanesh M, Sadaghi B, Silversides FG (2013) Influence of supplementation of diarrhea, probiotic, and antibiotic to wet-fed wheat-based diets on growth, ileal nutrient digestibility, blood parameters, and gastrointestinal characteristics of broiler chickens. J Clin Pathol 22:245-251

Bermudez-Brito M, Plaza-Díaz J, Muñoz-Quezada S, Gómez-Llorente C, Gil A (2012) Probiotic mechanisms of action. Ann Nutr Metab 61:160-174

Bhandari SK, Xu B, Nyachoti CM, Giesting DM, Krause DO (2008) Evaluation of alternatives to antibiotics using an Escherichia coli K88+ model of piglet diarrhea: effects on gut microbial ecology. J Anim Sci 86:836-847

Bruininx EMAM, Peetschwering VDCMC, Schrama JW (2001) Individual feed intake of group housed weaned pigs and health status? Weaner Pig Nutr Manag 122:1-25

Choi JY, Shinde PL, Ingale SL, Kim JS, Kim YW, Kim KH, Kwon IK, Chae BJ (2011) Evaluation of multi-microbe probiotics prepared by submerged liquid or solid substrate fermentation and antibiotics in weaning pigs. Livest Sci 138:144-151

Cui C, Shen CJ, Jia G, Wang KN (2013) Effect of dietary Bacillus subtilis on proportion of Bacteroidetes and Firmicutes in swine intestine and lipid metabolism. Genet Mol Res 12:1766-1776

Deng B, Wu J, Li XH, Men XM, Xu ZW (2017) Probiotics and probiotic metabolic product improved intestinal function and ameliorated LPS-induced injury in rats. Curr Microbiol 74:1306-1315

Dethlefsen L, Huse S, Sogin ML, Relman DA (2008) The pervasive effects of an antibiotic on the human gut microbiota, as revealed by deep $16 \mathrm{~S}$ rRNA sequencing. PloS Biol 6:e280

Dibner JJ, Richards JD (2005) Antibiotic growth promoters in agriculture: history and mode of action. Poult Sci 84(4):634-643

Ding H, Huang P, Zhang WM, He JH, Kong XF (2020) Effects of dietary Bacillus subtilis on growth performance and plasma biochemical parameters of nursery piglets. Chin J Anim Nutr 32:605-612 (in Chinese)

Driks A (2002) Overview: development in bacteria: spore formation in Bacillus subtilis. Cell Mol Life Sci 59:389-391 
Fairbrother JM, Nadeau E, Gyles CL (2005) Escherichia coli in postweaning diarrhea in pigs: an update on bacterial types, pathogenesis, and prevention strategies. Anim Health Res Rev 6:17-39

Giang HH, Viet TQ, Ogle B, Lindberg JE (2011) Effects of supplementation of probiotics on the performance, nutrient digestibility and faecal microflora in growing-finishing pigs. Asian Australas J Anim 24:655-661

Gracia MI, Hansen S, Sanchez J, Medel P, Agropecuaria SLI (2004) Efficacy of addition of $B$. licheniformis and $B$. subtilis in pig diets from weaning to slaughter. J Anim Sci 82:26

Guo X, Li D, Lu W, Piao X, Chen X (2006) Screening of Bacillus strains as potential probiotics and subsequent confirmation of the in vivo effectiveness of Bacillus subtilis MA139 in pigs. Anton Leeuw Int J Gen 90:139-146

Guo X, Xia X, Tang R, Zhou J, Zhao H, Wang K (2008) Development of a real-time PCR method for Firmicutes and Bacteroidetes in faeces and its application to quantify intestinal population of obese and lean pigs. Lett Appl Microbiol 47:367-373

He X, Yin H, Han L, Cui R, Fang C, Huang G (2019) Effects of biochar size and type on gaseous emissions during pig manure/wheat straw aerobic composting: insights into multivariate-microscale characterization and microbial mechanism. Bioresour Technol 271:375-382

Hu YL, Dun Y, Li SH, Zhao SM, Peng N, Liang YX (2014) Effects of Bacillus subtilis KN-42 on growth performance, diarrhea and faecal bacterial flora of weaned piglets. Asian Austral J Anim 27:1131-1140

Huo SY, Deng ZLY, Jiang JP (2017) Effects of antibiotics substitution agent Z-27 on intestinal digestive enzymes, nutrients and growth performance of weaned piglet. J Henan Agric Sci 46:125-129 (in Chinese)

Jørgensen JN, Laguna JS, Millán C, Casabuena O, Gracia MI (2016) Effects of a Bacillus-based probiotic and dietary energy content on the performance and nutrient digestibility of wean to finish pigs. Anim Feed Sci Technol 221:54-61

Kim JS, Ingale SL, Kim YW, Kim KH, Sen S, Ryu MH, Lohakare JD, Kwon IK, Chae BJ (2012) Effect of supplementation of multi-microbe probiotic product on growth performance, apparent digestibility, cecal microbiota and small intestinal morphology of broilers. J Anim Physiol Anim Nutr 96:618-626

Kritas SK, Morrison RB (2005) Evaluation of probiotics as a substitute for antibiotics in a large pig nursery. Vet Rec 156:447

Lee JH, Lee B, Lee HS, Bae EA, Lee H, Ahn YT, Lim KS, Huh CS, Kim DH (2009) Lactobacillus suntoryeus inhibits pro-inflammatory cytokine expression and TLR-4-linked NF-kappaB activation in experimental colitis. Int J Colorectal Dis 24:231-237

Lee SH, Ingale SL, Kim JS, Kim KH, Lokhande A, Kim EK, Kwon IK, Kim YH, Chae BJ (2014) Effects of dietary supplementation with Bacillus subtilis LS 1-2 fermentation biomass on growth performance, nutrient digestibility, cecal microbiota and intestinal morphology of weanling pig. Anim Feed Sci Technol 188:102-110

Liao SF, Nyachoti M (2017) Using probiotics to improve swine gut health and nutrient utilization. Anim Nutr 3(4):23-35

Looft T, Johnson TA, Allen HK, Bayles DO, Alt DP, Stedtfeld RD, Sul WJ, Stedtfeld TM, Chai B, Cole JR, Hashsham SA, Tiedje JM, Stanton TB (2012) In-feed antibiotic effects on the swine intestinal microbiome. Proc Natl Acad Sci USA 109:1691-1696

Martin MJ, Thottathil SE, Newman TB (2015) Antibiotics overuse in animal agriculture: a call to action for health care providers. Am J Public Health 105(12):2409-2410
McCann KS (2000) The diversity-stability debate. Nature 405:228-233

Molist F, Manzanilla EG, Pérez JF, Nyachoti CM (2012) Coarse, but not finely ground, dietary fibre increases intestinal Firmicutes: Bacteroidetes ratio and reduces diarrhea induced by experimental infection in piglets. $\mathrm{Br} \mathrm{J}$ Nutr 108:9-15

Mulder IE, Schmidt B, Stokes CR, Lewis M, Bailey M, Aminov RI, Prosser Jl, Gill BP, Pluske JR, Mayer CD, Musk CC, Kelly D (2009) Environmentallyacquired bacteria influence microbial diversity and natural inate immune responses at gut surfaces. BMC Biol 7:79

Pi DG, Liu YL, Shi HF, Li S, Odle J, Lin X, Zhu H, Chen F, Hou Y, Leng W (2014) Dietary supplementation of aspartate enhances intestinal integrity and energy status in weaning piglets after lipopolysaccharide challenge. J Nutr Biochem 25:456-462

Rajput IR, Li WF, Li YL, Lei J, Wang MQ (2012) Application of probiotic (Bacillus subtilis) to improve immunity, antioxidation, activity of digestive enzymes and haematological profile of shaoxing duck. Pak Vet J 33:69-72

Rajput IR, Li YL, Xu X, Huang Y, Zhi WC, Yu DY, Li W (2013) Supplementary effects of Saccharomyces boulardii and Bacillus subtilis B10 on digestive enzyme activities, antioxidation capacity and blood homeostasis in broiler. Int J Agric Biol 15:1560-8530

Resta-Lenert S, Barrett KE (2006) Probiotics and commensals reverse TNFalpha- and IFN-gamma-induced dysfunction in human intestinal epithelial cells. Gastroenterology 130:731-746

Shen YB, Piao XS, Kim SW, Wang L, Liu P, Yoon I, Zhen YG (2009) Effects of yeast culture supplementation on growth performance, intestinal health, and immune response of nursery pigs. J Anim Sci 87:2614-2624

Tsukahara T, Tsuruta T, Nakanishi N, Hikita C, Mochizuki M, Nakayama K (2013) The preventive effect of Bacillus subtilus strain DB9011 against experimental infection with enterotoxcemic Escherichia coli in weaning piglets. Anim Sci J 84:316-321

Wang Y, Cho JH, Chen YJ, Yoo JS, Huang Y, Kim HJ, Kim IH (2009) The effect of probiotic BioPlus 2B on growth performance, dry matter and nitrogen digestibility and slurry noxious gas emission in growing pigs. Livest Sci 120(1-2):35-42

Wang H, Kim KP, Kim IH (2019) Influence of Bacillus subtilis GCB-13-001 on growth performance, nutrient digestibility, blood characteristics, faecal microbiota and faecal score in weanling pigs. J Anim Physiol Anim Nutr 103:11-12

Weichselbaum E (2009) Probiotics and health: a review of the evidence. Nutr Bull 34:340-373

Zhou D, Zhu YH, Zhang W, Wang ML, Fan WY, Song D, Yang GY, Jensen BB, Wang JF (2015) Oral administration of a select mixture of Bacillus, probiotics generates $\operatorname{Tr} 1$ cells in weaned F4ab/acR-, pigs challenged with an F4+, ETECNTEC/EPEC strain. Vet Sci 46(1):95

Zouari R, Hamden K, Feki AE, Chaabouni K, Makni-Ayadi F, Kallel C, Sallemi F, Ellouze-Chaabouni S, Ghribi-Aydi D (2016) Protective and curative effects of Bacillus subtilis SPB1 biosurfactant on high-fat-high-fructose diet induced hyperlipidemia, hypertriglyceridemia and deterioration of liver function in rats. Biomed Pharmacother 84:323-329

\section{Publisher's Note}

Springer Nature remains neutral with regard to jurisdictional claims in published maps and institutional affiliations. 